\title{
Solar irradiance in the heterogeneous albedo environment of the Arctic coast: measurements and a 3-D model study
}

\author{
A. Kreuter ${ }^{1}$, R. Buras ${ }^{2}$, B. Mayer ${ }^{2}$, A. Webb ${ }^{3}$, R. Kift ${ }^{3}$, A. Bais ${ }^{4}$, N. Kouremeti ${ }^{4,5}$, and M. Blumthaler $^{1}$ \\ ${ }^{1}$ Division for Biomedical Physics, Innsbruck Medical University, Innsbruck, Austria \\ ${ }^{2}$ Meteorologisches Institut, Ludwig-Maximilians-Universität, Munich, Germany \\ ${ }^{3}$ School of Earth Atmospheric and Environmental Sciences, University of Manchester, Manchester, UK \\ ${ }^{4}$ Laboratory of Atmospheric Physics, Aristotle University of Thessaloniki, Thessaloniki, Greece \\ ${ }^{5}$ Physikalisch-Meteorologisches Observatorium / World Radiation Center, Davos, Switzerland
}

Correspondence to: A. Kreuter (axel.kreuter@i-med.ac.at)

Received: 2 December 2013 - Published in Atmos. Chem. Phys. Discuss.: 6 February 2014

Revised: 16 April 2014 - Accepted: 24 April 2014 - Published: 18 June 2014

\begin{abstract}
We present a unique case study of the solar global irradiance in a highly heterogeneous albedo environment at the Arctic coast. Diodearray spectroradiometers were deployed at three sites around Ny Ålesund, Svalbard, and spectral irradiances were simultaneously measured under clearsky conditions during a $24 \mathrm{~h}$ period. The 3 -D radiative transfer model MYSTIC is applied to simulate the measurements in various model scenarios. First, we model the effective albedos of ocean and snow and consequently around each measurement site. The effective albedos at $340 \mathrm{~nm}$ increase from 0.57 to 0.75 , from the coastal site in the west towards the site $20 \mathrm{~km}$ east, away from the coast. The observed ratios of the global irradiance indicate a $15 \%$ higher average irradiance, at $340 \mathrm{~nm}$ east relative to west, due to the higher albedo. The comparison of our model scenarios suggest a snow albedo of $>0.9$ and confirm the observation that drift ice has moved into the Fjord during the day. The local time shift between the locations causes a hysteresis-like behavior of these east-west ratios with solar zenith angle (SZA). The observed hysteresis, however, is larger and, at $340 \mathrm{~nm}$, can be explained by the drift ice. At $500 \mathrm{~nm}$, a plausible explanation is a detector tilt of about $1^{\circ}$. The ratios between afternoon and morning irradiances at the same SZA are investigated, which confirm the above conclusions. At the coastal site, the measured irradiance is significantly higher in the afternoon than in the morning. Besides the effect of changing drift ice and detector tilt, the small variations of the aerosol optical depth have to be considered also at the other stations to reduce the
\end{abstract}

discrepancies between model and observations. Remaining discrepancies are possibly due to distant high clouds.

\section{Introduction}

The reflectivity of the Earth's surface, the albedo, is a significant factor in the global radiation budget. Reflected solar radiation increases the sky's radiance due to multiple scattering of air molecules (Kylling and Mayer, 2001). Snow is amongst the most reflective surfaces, above which the solar global irradiance can be enhanced by up to $50 \%$ in the UV under clear-sky conditions (Blumthaler, 2007; Bernhard et al., 2007; Lenoble, 1998). With aerosol and in particular with clouds, the enhancement can be even higher (McKenzie et al., 1998).

While the clear-sky radiation field over a homogeneous albedo environment is well understood and can be simulated with one-dimensional (1-D) radiative transfer models, the situation of inhomogeneous spatial albedo is a much more challenging task requiring three dimensions (3-D) in the radiative transfer model. In particular the Arctic coastal region is one such situation of significant complexity due to high albedo inhomogeneity: the dark sea and the highly reflecting snow create an almost digital albedo pattern, which manifests itself in the sky radiance.

Due to multiple scattering, the sky can be understood as a diffusive mirror with a "diffusion constant" dependent on atmospheric conditions. Under a stratus cloud deck, the 
diffusion constant is so small that open water or sea leads (polynyas) surrounded by snow are clearly visible (with the eye) as dark patches in the cloud deck (Overland et al., 1995), an effect that has been used by seafarers for navigating sea ice in Arctic waters. Sky radiance measurements at the Antarctic coast under clear-sky conditions, also showed a brightening of the sky over the snow covered land with respect to the sea (Ricchiazzi et al., 2002). Such an asymmetry in the radiance has also been observed at the high-altitude station of Jungfraujoch in Switzerland (Huber et al., 2004) with the glacier on the one side and the snow free valley on the other side.

More generally, up- and downwelling radiation in Arctic coastal regions in the UV is relevant for assessing the radiation impact on the coastal marine biology especially with respect to photobiological processes in phytoplankton as a pivotal part of the marine ecosystem (Kirk, 1994). Also, satellite remote sensing of the atmosphere near the coast needs to include the albedo effects on the radiation field. Therefore, solar radiation measurements in such complex albedo environments are not only important for monitoring and satellite validation purposes but also interesting with respect to 3-D model comparisons in order to enhance our understanding of the various factors impacting the radiation field. The latter is the subject of this work.

An inhomogeneous albedo pattern is not only evident in the sky radiance distribution measured at one location but consequently also affects the spatial variation of global solar irradiances measured simultaneously at different locations. A benchmark setting for the investigation of the spatial scale on which the albedo affects the irradiance is a pronounced albedo step transition. The Arctic coasts offer such an ideal feature; however, due to their remoteness and consequent infrastructural challenges and harsh environmental conditions, only few observations have been reported in the past.

The erythemally weighted UV irradiance (UV-index) was measured under clear-sky conditions on a line transecting the Antarctic coast (Smolskaia et al., 1999) and quantified a $10 \%$ increase of the irradiance over a distance of $5 \mathrm{~km}$. The measurements were not conclusive, in particular because the transect lines were not long enough for the irradiances to reach asymptotic values (Mayer and Degünther, 2000). Global irradiances were measured also with three broadband UV radiometers at the Antarctic coast line under variable overcast conditions, which obscures conclusions about the coastal effect on the irradiance (Lubin et al., 2002). Another relevant measurement campaign was conducted around the Salar de Uyuni on the Bolivian Altiplano where a reflective dry salt lake creates a high-albedo transition. Two locations inside and outside the lake were compared and the erythemally weighted UV irradiance was enhanced by around $20 \%$ in agreement with 1-D model calculations and spatially averaged albedos (Reuder et al., 2007).

Several pure model studies dedicated to the global irradiance in the inhomogeneous albedo environment have been reported. In a detailed 3-D modeling study, Ricchiazzi and Gautier (1998) have investigated the Antarctic coast and have shown how the irradiances are affected by the albedo of distant regions and how this "region of interest" depends on atmospheric conditions. Another model study of the Antarctic coastline under cloud cover shows in particular the sensitivity to cloud properties (Podgorny and Lubin, 1998). Degünther et al. (1998) and Degünther and Meerkötter (2000) investigated the albedo influence for some more general situations using simple example geometries.

So the detailed influence of the spatial distribution of the global solar irradiance over an underlying inhomogeneous albedo distribution is an on-going field of research. The motivation for a field campaign at the Arctic coast was to contribute a new multidimensional data set: simultaneous spectra at three locations over the course a cloudless day on the peninsula around Ny Ålesund, Svalbard, to compare the spectral, temporal and spatial variation of the global irradiance with 3-D model simulations.

In the following, we set out by describing the campaign and its setting and the 3-D model. The albedo environments around the measurement locations are illustrated by modeled effective albedos. We then present the measurement results and discuss them in the context of various plausible model scenarios, in particular regarding variable albedo and atmospheric conditions.

\section{The measurement campaign}

Spectral measurements of the global irradiance were made during a 3-week field campaign based in Ny Ålesund, Svalbard, in spring 2009. Three diode array (DA) spectroradiometer systems were used to record synchronous spectra in the UV-visible (UV-VIS) spectral range 300-890 nm every $5 \mathrm{~min}$ (starting at the full hour) with an integration time of $100 \mathrm{~s}$ for each spectrum.

The spectroradiometers were deployed at three sites, spatially distributed roughly along the direction of the albedo gradient, with increasing distance from the coastline towards the snow covered land with a horizontal distance of about $20 \mathrm{~km}$. The first site (west) was set up $12 \mathrm{~km}$ to the northwest of Ny Ålesund at the coast of the Kongsfjord and was characterized by the lowest albedo surrounding. The next site (center) was set up on the roof of the Norwegian Polar Institute (NPI) in Ny Ålesund. Located close by, a quality assured scanning spectroradiometer was operated by the Alfred Wegener Institute (AWI) (Gröbner et al., 2010). The third site (east), $7 \mathrm{~km}$ further to the southeast towards the Kongsvegen glacier, constituted the highest albedo surrounding. The topography and albedo distribution around the three stations are depicted in Fig. 1 and a panoramic webcam image is shown in Fig. 2a.

The DA spectroradiometer at station west (Ocean Optics, USB4000) has a 16 bit dynamic range and 3648 pixels over 


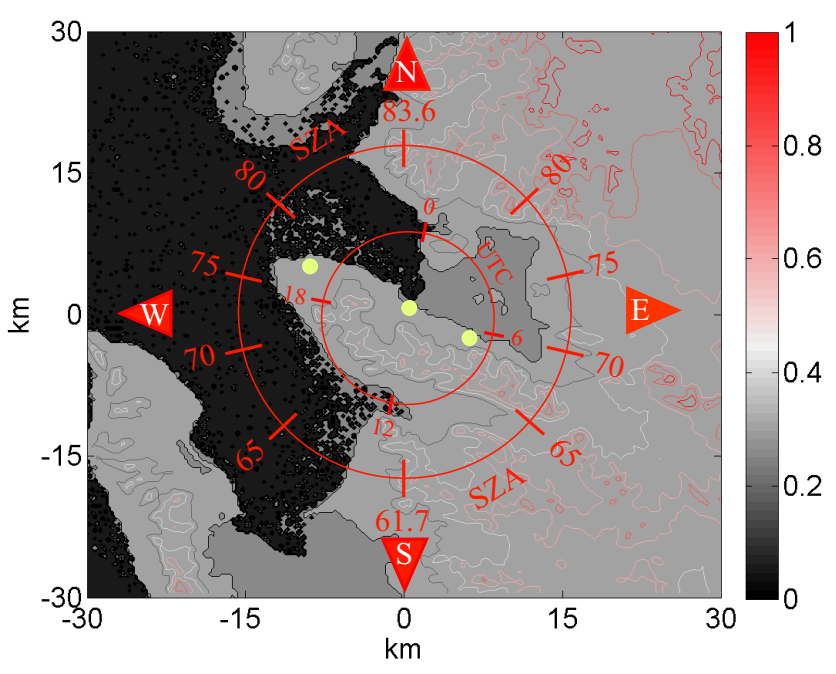

Figure 1. Topography and albedo distribution around the three measurement sites (green dots), west, center and east, named according to their relative geographical position. The ocean is colored black, and snow covered land is colored gray, while ice in the partly frozen Fjord is colored with a darker shade of gray for illustration, but is assigned the same albedo as snow in our model scenarios. The color bar refers to the elevation contour lines (in $\mathrm{km}$ ). For all solar azimuth angles, the corresponding SZA and time are shown on the compass dial.

the range $180-890 \mathrm{~nm}$ and an average slit width of $1.7 \mathrm{~nm}$ full width at half maximum (FMHM) (Kreuter and Blumthaler, 2009). The DA spectroradiometer at station center (Zeiss, MCS-CCD) has a 16 bit dynamic range and 1044 pixels over the range $310-1000 \mathrm{~nm}$ and an average slit width of $2 \mathrm{~nm}$ FWHM (Kouremeti et al., 2008). The DA spectroradiometer at station east (Ocean Optics, S2000) has a 12 bit dynamic range and 2048 pixels over the range $190-850 \mathrm{~nm}$ and an average slit width of $1.2 \mathrm{~nm}$ FWHM. All instruments were temperature-controlled in a weatherproof housing and fitted with the same type of cosine-weighting diffusers as input optics.

Our global irradiance measurements were complemented by additional instruments: an all-sky imager, a digital camera with a fish eye objective (Kreuter et al., 2009), was moved between the measurement sites to capture photos of the sky and record cloud conditions. A multi-filter radiometer was used as an independent stability check of the DA spectroradiometers. The infrastructure of the international research site at Ny Ålesund is well established and supplies an abundance of atmospheric data. Particularly relevant here are the sun photometer measurements of the aerosol optical depth (AOD), which are publicly available within the global atmospheric watch (GAW) network. Detailed ice charts showing the ice condition of the Kongsfjord was available from the Norwegian Met service. We also used the webcam images from the Zeppelin mountain above Ny Ålesund showing the Kongsfjord.

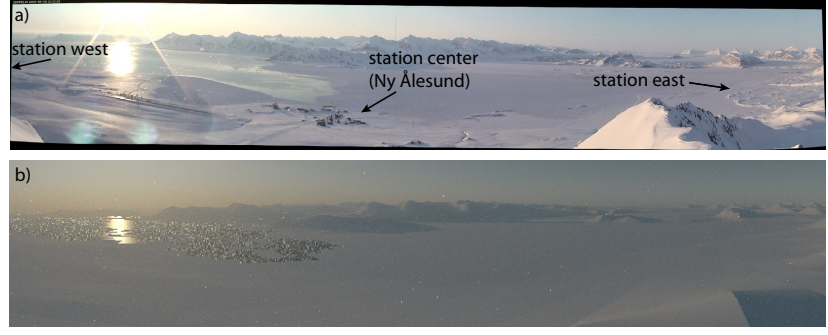

Figure 2. (a) Webcam view towards the north from Zeppelin mountain overlooking Ny Ålesund on 8 May 2009, 22:00 UTC. The locations of two stations are visible, station west is further to the west. Due to low wind speed, a pronounced sun glint is visible over the ocean. (b) With MYSTIC, the simulated radiances (RGB) with a BRDF model for water reflection (Cox and Munk, 1954, with $2 \mathrm{~m} \mathrm{~s}^{-1}$ wind speed) show the same effect and indicate a realistically modeled scene.

All DA spectroradiometers were radiometrically calibrated with the same calibration lamp as the absolute reference standard. While co-located at Ny Ålesund, before and after field deployment, all instruments were intercompared for several days under various sky conditions. Regular calibrations were also performed for each instrument in the field, to monitor their stability. The relative radiometric stability of each instrument was better than $1 \%$ over the entire day.

Data post processing of the DA measurements include the following steps. After dark current subtraction, the spectra are stray light corrected. The spectra from the DA at station west were corrected with a matrix method (Kreuter and Blumthaler, 2009). Spectra from stations east and center were corrected with a simplified technique using modeled spectra to estimate the stray light. We estimate an uncertainty due to a residual stray light error at $340 \mathrm{~nm}$ of $<2 \%$ at $80^{\circ} \mathrm{SZA}$.

Since the different instruments have slightly different slit widths, all spectra are deconvolved and convolved with a triangular slit function of a $1 \mathrm{~nm}$ width (Slaper et al., 1995). Finally, the spectra are corrected for deviations from the ideal cosine response of the input optics. For each instrument, the measured cosine response functions, measured carefully in laboratory before and after the campaign, were applied. The azimuth error of the global input optics cannot be corrected in retrospect (since the optics were not oriented in a specific direction) and is about $5 \%$ at $500 \mathrm{~nm}$ for direct solar radiation. By considering the direct contribution to the global irradiance (given below in section 3.2), the expected maximum uncertainty for each instrument is 1.5 and $1 \%$ for the global irradiance at $70^{\circ}$ and $80^{\circ} \mathrm{SZA}$, respectively, for $500 \mathrm{~nm}$ and $<1 \%$ for $340 \mathrm{~nm}$. 


\section{The radiative transfer model}

\subsection{General description}

The radiative transfer (RT) simulations were performed with the 3-D Monte Carlo model MYSTIC (Mayer, 2009; Mayer et al., 2010). A 1-D version of MYSTIC is included in the freely available libRadtran package (Mayer and Kylling, 2005). In backward mode, MYSTIC randomly traces photons originating from the detector through the atmosphere. At each scatter or surface reflection event, a local estimate is performed, that is, the probability that the photon is scattered/reflected towards the sun and reaches the sun without being extinct is calculated. The sum over all local estimates, divided by the number of simulated photons, gives the transmittance. The global irradiance is the transmittance multiplied with the extraterrestrial irradiance and weighted by the cosine of the SZA.

The spectral irradiances are computed for the three measurement locations for the relevant day, in accordance with the exact measurement schedule. The median of each measurement period of 100 seconds was taken as the time basis for the model input. Each simulated irradiance is a result of $2 \times 10^{7}$ sampled photons ensuring a statistical uncertainty of $<0.1 \%$ standard deviation.

The atmosphere is assumed cloud free (except for one specific scenario) and stratified with a standard AFGL vertical profile of subarctic summer (Anderson et al., 1986). Aerosol properties are specified according to Shettle (1989), rural type (with the extinction scaled to the measured AOD). MYSTIC allows either calculations including topography or spherical atmosphere but currently not in combination. So we work with a plane-parallel (PP) atmosphere, which is well justified here, even for SZA $>80^{\circ}$, since we will consider only ratios of irradiances. Without topography, the negligible effect of the PP-approximation on the ratios has been checked.

The 2-D surface is specified by a $600 \mathrm{~km} \times 600 \mathrm{~km}$ grid with a $250 \mathrm{~m}$ resolution. The elevation at each grid point has been taken from a digital elevation map based on the Shuttle Radar Topography Mission (SRTM). The grid points are interpolated bi-linearly so that each grid element is a tilted and bent surface. Each grid element also has surface reflection property given by the bidirectional reflectance distribution function (BRDF). Here, we need to consider two BRDFs: one for water (ocean) and one for snow (land).

Water reflection is commonly modeled by the parameterized function of wind speed and direction by Cox and Munk (1954). A striking feature of an ocean reflection is the specular reflection of the sun, especially at low solar elevations. This so-called sun glint is an interesting effect to be investigated by a 3-D model. From a comparison of the sun glint shape in webcam images and simulated photos (Fig. 2), we can estimate the wind speed to be about $2 \mathrm{~m} \mathrm{~s}^{-1}$. This is consistent with local wind measurements in Ny Ålesund, which were always below $2.5 \mathrm{~m} \mathrm{~s}^{-1}$, from easterly directions in morning and westerly directions in the afternoon.

However, the sharp forward peak of the sun glint scattering causes a problem with the convergence of the MC model. When photons scatter on the water surface with the corresponding angle of incidence, the probability of scattering into the direction of the sun is very high, otherwise it is close to zero. So very few photons will obtain very large weights which results in rare but signal-dominating local estimate contributions (spikes) and slow down the convergence considerably. Furthermore, the Cox and Munk (1954) model $\mathrm{BRDF}$ is not suited for $\mathrm{SZA}>80^{\circ}$ (C. Gatebe, private communication, 2012).

In order to solve both these problems and ensuring a physically correct model, we approximate the ocean as a completely flat water surface and apply Fresnel's equations (e.g., Hecht, 2002). The complex index of refraction for water is taken from Hale and Querry (1973). The BRDF is now a delta function and the spikes can be eliminated by implementing the variance reduction method called double local estimate (DoLE) (Marchuk, 1980). Whenever a photon scatters, we calculate the probability that the photon scatters towards the direction of the sun reflection in the ocean, reaches the ocean without being extinct, specularly reflects towards the sun, and reaches the sun without being extinct. If the reflection takes place over the ocean only the DoLE contribution is taken into account and no local estimate, to prevent double counting of photons. We compared the modeled irradiances with a Cox and Munk (1954) water surface at $2 \mathrm{~m} \mathrm{~s}^{-1}$ wind speed and a flat water surface and found an agreement within $1 \%$, which justifies our Fresnel approximation.

For the snow BRDF, we use the parameterization by Rahman, Pinty and Verstraete (RPV) (Rahman et al., 1993) with the slight modifications and additional parameters implemented by Degünter et al. (2000). The RPV BRDF is slightly anisotropic to accommodate for the forward scattering of snow and weak "hot spot" in the backward scattering direction. It was noted by Degünter et al. (2000), and was confirmed in this study, that the anisotropy of the snow BRDF has a negligible effect on the global irradiance. The only discernible trait of the BRDF is that the albedo is dependent on the SZA which is not the case for a Lambertian surface. This dependency vanishes for the mainly diffuse sky radiance at short wavelengths.

In addition to the land, parts of the coastal waters and especially the Fjords on Svalbard are partly frozen and covered with snow. Detailed ice charts are issued daily by the Norwegian Meteorological Institute. The charts are daily means centered at 12:00 UTC and classify areas into five categories associated with an ice coverage range given in tenth: open waters $(0-1 / 10)$, very open drift ice (1/10-4/10), open drift ice $(4 / 10-7 / 10)$, etc. Each pixel of our ocean is assigned either snow BRDF (ice classified areas are modeled as snow albedo) or water BRDF with the mean probability of the given category. 


\subsection{Model scenarios}

Since some of the input parameters are associated with some uncertainty, we model multiple scenarios considering the range of plausible values for these parameters. This also helps with understanding the individual effects of each parameter. As a starting point for our model simulations, we consider the albedo distribution from the ice map and the measured mean AOD. For the snow BRDF we use the parameters of Degünther et al. (2000). The parameter $\rho_{0}=0.728$ controls the albedo and corresponds to an equivalent Lambertian albedo of 0.81 . We will call this the "standard" scenario.

The local albedo of snow is expected in the range 0.70.99 for the shortwave spectral range (e.g., Blumthaler and Ambach, 1988) depending on snow type and condition. The highest values close to one are typically reported for pure and fresh Antarctic snow (Wiscombe and Warren, 1980; Wuttke et al., 2006). Arctic albedos are generally a little lower, and average daily mean albedos as low as 0.8 have been reported for spring time in Ny Ålesund (Wang and Zender, 2011). We model all land-classified pixels in our model as snow, and the spatial average of the albedo over a large area tends to be a little lower than local measurements, considering that a few dark rocks may protrude from the snow. The clean snow conditions during our campaign justify a model scenario with a higher albedo $\left(\rho_{0}=0.801\right)$, corresponding to an equivalent Lambertian albedo of 0.86 ("high albedo" scenario). This is well within the range of a reasonable average albedo.

Then, we consider a variability in ice distribution. In fact, the hourly webcam images from Zeppelin mountain south of Ny Ålesund indicate changing drift ice conditions (Fig. 3), with ice moving into the Fjord over the course of the day, which also corresponds to the change in wind direction around 12:00 UTC. The exact ice distribution is too complex to model from the images alone without additional more detailed, quantitative observations, but we can estimate the effect of variable drift ice by modeling a scenario with a locally ice-free Fjord in the morning. In this scenario (no ice), the ocean is set ice free for a $20 \mathrm{~km} \times 10 \mathrm{~km}$ rectangular area north of station west.

A further issue of interest is the effect of AOD. The AOD on the measurement day was low and characterized by the mean Ångstrom parameters $\alpha=1.77$ and $\beta=0.034$, where $\alpha$ is the so-called Angstrom exponent determining the wavelength dependency of AOD and $\beta$ is the AOD at $1000 \mathrm{~nm}$. The corresponding mean $\mathrm{AOD}$ at $500 \mathrm{~nm}\left(\mathrm{AOD}_{500}\right)$ was 0.12 with a slight diurnal variability. Between 05:00 and 21:00 UTC, the $\mathrm{AOD}_{500}$ varied little between 0.115 and 0.125 , while in the morning around 02:30 UTC the AOD500 was highest at 0.17 . This might have a measurable effect on the global irradiance. So we model all scenarios with a constant mean AOD and an "aerosol" scenario considering the real temporal AOD variation over the day.

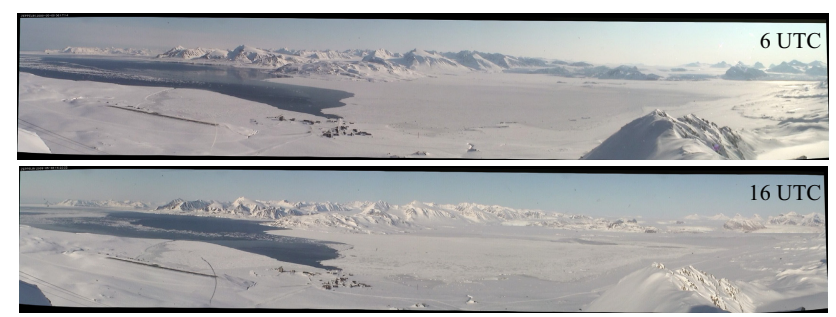

Figure 3. Webcam view from Zeppelin mountain on 8 May 2009, 06:00 and 16:00 UTC. More drift ice is visible in the western outer part of the Fjord in the morning. High clouds appear faintly on the northwestern horizon. Note the changing brightness of the snow on the frozen Fjord relative to the snow covered land.

We also model the effect of a non-perfect leveling of the detectors, ("tilt" scenario) and we consider a flat land surface to illustrate the effect of the topography (no topo). Finally, we also model a "cloud" scenario. High clouds were faintly visible in our all-sky camera images as well as on the webcam images from Zeppelin mountain between 01:00 and 06:00 UTC on the horizon northwest of Ny Alesund (see also Fig. 3). In our cloud scenario, we set up a homogeneous cirrostratus cloud with a straight boundary line at an angle of $22.5^{\circ}$ counterclockwise to the east-west direction and extending into the northwest sector. The cloud is at an altitude between 4 and $5 \mathrm{~km}$ with an effective radius of $40 \mu \mathrm{m}$ and an ice water content of $0.00246 \mathrm{~g} \mathrm{~m}^{-3}$ which yields an optical depth of 1 . Since this scenario is based on somewhat arbitrary assumptions, albeit plausible, we use the result only as a guideline to estimate the magnitude of the effect of clouds that are far enough to not significantly perturb the local clearsky perception.

The model scenarios are summarized in Table 1. For the following studies, we focus on two wavelengths $340 \mathrm{~nm}$ and $500 \mathrm{~nm}$, compatible with reliable measurements and constituting two interesting cases, one with more diffuse and one with more direct components of the global irradiance, respectively. The ratio of direct to global (direct + diffuse) down welling irradiance for $340 \mathrm{~nm}$ and $500 \mathrm{~nm}$ is 0.12 and 0.58 at $70^{\circ} \mathrm{SZA}$, respectively; the ratio is 0.01 and 0.35 at $80^{\circ}$ SZA, respectively. These direct/global ratios are computed for albedo 0.5 , but the ratios are only weakly dependent on albedo.

\section{Effective albedos}

An inhomogeneous albedo distribution is an intrinsic 3-D problem for modeling the solar irradiance. When only a 1-D model is available or computation time is critical, the irradiance can also be modeled using the concept of an effective albedo (Weihs et al., 2001). The effective albedo is a spatially averaged homogeneous albedo that, for a 1-D calculation, yields the same irradiance as the 3-D model. We derived 
Table 1. Relevant input parameters for each modeled scenario with respect to land, ocean and atmosphere characteristics. Bold text indicates the respective parameter that has been modified for the scenario. $\rho_{0}$ is the albedo parameter in the snow RPV model, $\alpha$ and $\beta$ are the aerosol Ångstrom parameters.

\begin{tabular}{|c|c|c|c|c|}
\hline Scenario & Land & Ocean & Atmosphere & Detectors \\
\hline "standard" & $\begin{array}{l}\text { Topography, } \\
\text { RPV, } \rho_{0}=0.728\end{array}$ & Ice map & $\begin{array}{l}\alpha=1.77 \\
\beta=0.034 \\
\text { Clear sky }\end{array}$ & All detectors level \\
\hline "high albedo" & $\begin{array}{l}\text { Topography, } \\
\text { RPV, } \rho_{0}=0.801\end{array}$ & Ice map & $\begin{array}{l}\alpha=1.77 \\
\beta=0.034 \\
\text { Clear sky }\end{array}$ & All detectors level \\
\hline "no ice" & $\begin{array}{l}\text { Topography, } \\
\text { RPV, } \rho_{0}=0.728\end{array}$ & $\begin{array}{l}\text { Fjord north of west } \\
\text { is ice free before } \\
\text { 12:00 UTC }\end{array}$ & $\begin{array}{l}\alpha=1.77 \\
\beta=0.034 \\
\text { Clear sky }\end{array}$ & All detectors level \\
\hline "aerosol" & $\begin{array}{l}\text { Topography, } \\
\text { RPV, } \rho_{0}=0.728\end{array}$ & Ice map & $\begin{array}{l}\text { Diurnal variation from } \\
\text { sun photometer }\end{array}$ & All detectors level \\
\hline "tilt" & $\begin{array}{l}\text { Topography, } \\
\text { RPV, } \rho_{0}=0.728\end{array}$ & Ice map & $\begin{array}{l}\alpha=1.77 \\
\beta=0.034 \\
\text { Clear sky }\end{array}$ & Detector west tilted $0.5^{\circ}$ west \\
\hline "no topo" & $\begin{array}{l}\text { No topography, } \\
\text { RPV }, \rho_{0}=0.728\end{array}$ & Ice map & $\begin{array}{l}\alpha=1.77 \\
\beta=0.034 \\
\text { Clear sky }\end{array}$ & All detectors level \\
\hline “cloud" & $\begin{array}{l}\text { Topography, } \\
\text { RPV, } \rho_{0}=0.728\end{array}$ & Ice map & $\begin{array}{l}\alpha=1.77 \\
\beta=0.034 \\
\text { Stratus cloud }\end{array}$ & All detectors level \\
\hline
\end{tabular}

the effective albedos by comparing the modeled 3-D irradiances with 1-D model calculations for a matrix of SZA and equivalent Lambertian albedos stored in a lookup table. For our standard scenario, we discuss the modeled effective albedos first for each surface type separately, ocean and water, and then for each station.

The water effective albedo (Fig. 4) is low at around 0.1 at $340 \mathrm{~nm}$ and independent of SZA, while at $500 \mathrm{~nm}$ the albedo increases from 0.1 to 0.6 with increasing SZA in the range $64-84^{\circ}$ (the water's reflectivity increases strongly for decreasing angles of incidence). This feature is even more prominent for longer wavelengths. This so-called sun glint only occurs for long wavelengths because of the high direct component of the global irradiance. At short wavelengths the diffuse radiance is dominant and the reflection is independent of SZA. For the modeled scenarios one must keep in mind that the effective albedo of the ocean is increased by the drift ice in the Fjord.

As an aside, we noticed that for SZA $>84^{\circ}$ and wavelengths longer than $650 \mathrm{~nm}$, the albedo exceeds one. Although it seems unphysical, we understand it as a result of the sharp forward peak in the BRDF, the sun glint. Virtually all solar radiation is reflected at a low angle, so the photons travel a long path through the atmosphere with an increased chance of backscattering. In the Lambertian reflection, a higher proportion is reflected into the direction of the zenith, which constitutes the shortest path through the atmosphere. This effect illustrates the limits of the effective albedo concept (Lambertian by definition) and 1-D modeling.
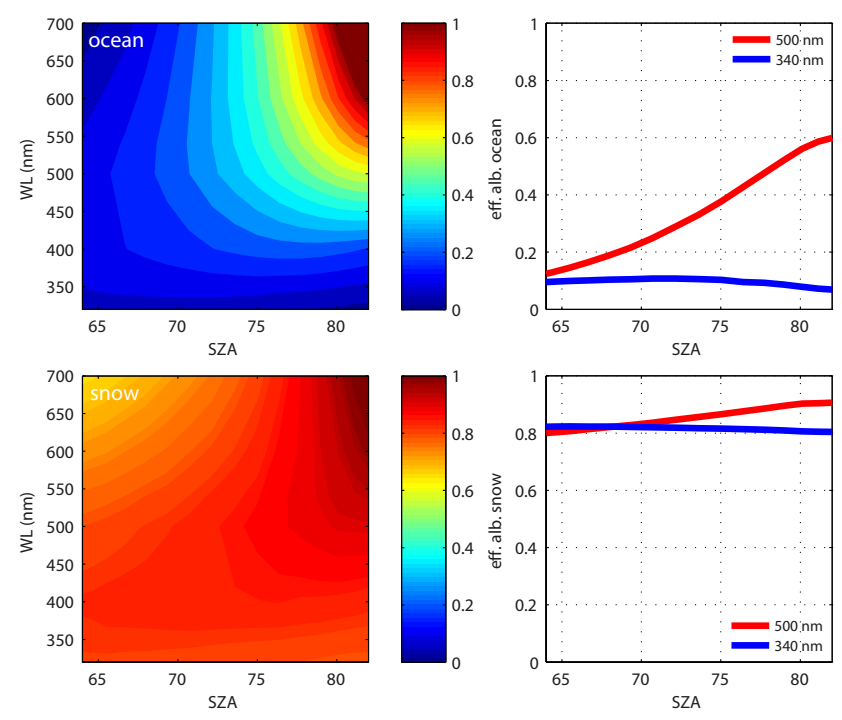

Figure 4. The effective albedo of water and snow as a function of SZA and wavelength. The right panels show slices at the two wavelengths $340 \mathrm{~nm}$ and $500 \mathrm{~nm}$. Note the strong sun glint for the ocean at high SZA and wavelength.

The effective snow albedo in the standard scenario is about 0.81 at $340 \mathrm{~nm}$ and essentially independent of SZA, resembling a Lambertian surface. For longer wavelengths $(500 \mathrm{~nm})$, the albedo becomes SZA dependent and increases from 0.8 at $65^{\circ}$ SZA to 0.9 at $84^{\circ}$ SZA. Since the RPV 

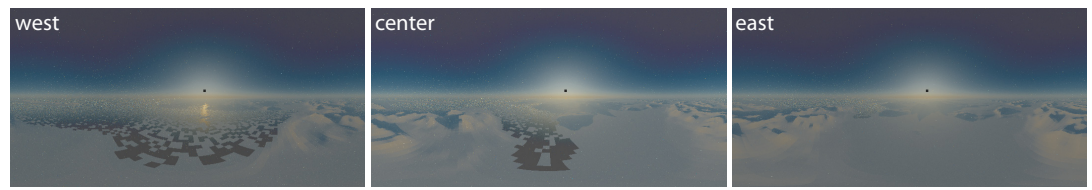

Figure 5. Simulated $360^{\circ}$ views (RGB radiances) for the standard scenario from $2.5 \mathrm{~km}$ above each station, zenith to nadir. The sun is in the north (black dot). The views nicely illustrate the different albedo environment at each station (increasing albedo from west to east) and the sun glint at station west.

parameters for the snow BRDF are taken as spectrally constant, this spectral difference has to be understood as a result of different sky radiance distributions: shifting from the diffuse to the direct sun regime with increasing wavelength.

Diurnal variation of snow albedo can also be affected geometrically by anisotropic snow surface structures (e.g., socalled sastrugi) formed by wind erosion (e.g., Warren et al., 1998). Sastrugi are common around Ny Ålesund roughly in east-west direction (König-Langlo and Herber, 2006), and have been noted to some extent during our campaign as well. Wang and Zender (2011) have measured the broadband shortwave albedo in Ny Ålesund for clear-sky days in April 2003-2008 and associate the observed symmetric diurnal variation of snow albedo (the minimum at local solar noon is about 0.12 lower than in the morning or afternoon) with sastrugi. The magnitude of this variation, however, is comparable to the SZA dependence of the effective albedo at $500 \mathrm{~nm}$ from the RPV snow model (Fig. 4). Also, Carroll and Fitch (1981) have reported shortwave albedo measurements from Antarctica and presented a parametric albedo model which exhibits a diurnal albedo variation of 0.15 . They infer that the sastrugi, which were prominent in the measurement area, may only affect the albedo by a maximum of $4 \%$. Furthermore, this geometric effect is only relevant for direct illumination, i.e., in our case for $500 \mathrm{~nm}$, where on the other hand the albedo amplification factor (see section 5.1) is so low that the effect on the global irradiance is not significant $(<1 \%)$.

Of course also the microphysical properties (snow grain size) of the snow pack can undergo change, typically during melting and freezing cycles, which causes diurnal albedo variations. Such variations have been observed on Arctic snow in Finland (Meinander et al., 2008). On our measurement day, the air temperature varied between a minimum of $-8^{\circ} \mathrm{C}$ and a maximum of $-5^{\circ} \mathrm{C}$, so no melting effects are expected.

Finally, regarding snow albedo, we noticed a peculiarity in the webcam images from the Zeppelin mountain overlooking Ny Ålesund (Fig. 3). In the morning at 6:00 UTC, the boundary of the frozen and snow covered Fjord and the snow covered land is clearly visible. The snow on the ice appears a little darker than the snow on the land indicating a different BRDF. The situation is reversed in the afternoon. The estimated snow depth on the ice and on the land is at least
$0.5 \mathrm{~m}$ with recorded temperatures always below $-5^{\circ} \mathrm{C}$. We have discussed this observation with some snow physicists but no plausible explanation has yet emerged, making it hard to quantify its possible effect on our model results.

Using the same lookup table method as for the snow and ocean effective albedos, we now determine the effective albedos for each station, considering the elevation map and ocean-snow distribution. The characteristic albedo environment is well visualized in the simulated radiances from above each station in Fig. 5. To simulate the sky color, we calculated radiance distributions for the complete visible wavelength region $380-780 \mathrm{~nm}$ and converted them to RGB values following Walker (2003).

The effective albedos (Fig. 6) show an interesting characteristic diurnal variation, again dependent on wavelength. Station west, situated close to the coast, exhibits the lowest albedo of about 0.57 at $340 \mathrm{~nm}$. It varies little over the day $( \pm 0.01)$, as expected, since both snow and water have essentially SZA independent effective albedos at this wavelength. Directly on an idealized, infinitely long, straight coast line the effective albedo would be 0.46 , the geometric mean of snow and water albedo. From west to east, the stations are further away from the ocean and more and more surrounded by snow. So the effective albedo at $340 \mathrm{~nm}$ increases up to 0.75 at east, approaching the asymptotic value of 0.81 .

At high wavelengths (as for $500 \mathrm{~nm}$ ), the effective albedos show a strong dependence not only on SZA but also on solar azimuth angle (i.e., it shows a hysteresis-like behavior with SZA over the course of the day). In the morning, the sun is in the east over the snow covered land, in the afternoon the sun is over the ocean and produces a strong sun glint. This increases the albedo in the west from 0.65 in the morning to 0.87 in the afternoon at $80^{\circ} \mathrm{SZA}$. In the east further away from the coast, the effect is less, and the albedo increases from 0.77 to 0.93 . Again, the effective albedo is higher than one for high wavelengths and SZA, which is an effect of the water BRDF as discussed above.

Finally, we have modeled the spatial distribution of irradiances on a $60 \mathrm{~km} \times 60 \mathrm{~km}$ grid with a $1 \mathrm{~km}$ resolution around the measurement sites ("standard" scenario for a SZA of $62^{\circ}$, i.e., at local noon with the sun in the south). Again using the lookup table method, we have converted the irradiance distribution to an effective albedo distribution (Fig. 7). This allows a comprehensive illustration of how the effective albedo 

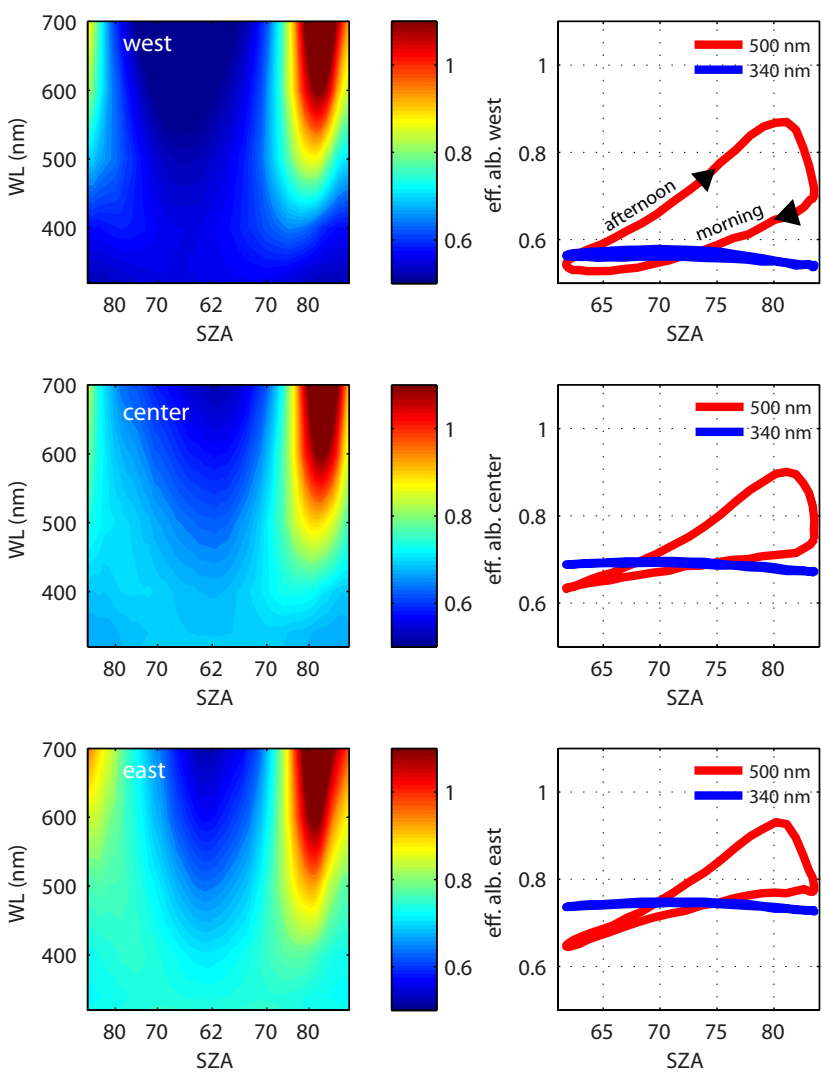

Figure 6. The effective albedo of stations west, center and east as a function of SZA and wavelength. The sun glint causes an increased albedo at high SZA and wavelengths, especially at station west. The right panels show slices at the two wavelengths 340 and $500 \mathrm{~nm}$. Effective albedos at $340 \mathrm{~nm}$ are constant to within 0.02 over the day.

varies over the albedo step transition at the Arctic coast and gradually increases with increasing distance inland from the coast.

Note that for the regions further than about $15 \mathrm{~km}$ inland, especially in the northwest, the effective albedo is modified by the topography. This is an artifact caused by the irradiances in the lookup table that were calculated for sea level, which strictly applies only for the vicinity of the measurement sites. The increase of irradiance with altitude in turn causes this increase of effective albedo.

\section{Results and discussion}

Instruments were operating simultaneously in the field for a week, out of which one clear-sky day (8 May 2009) was suitable for this study. Global irradiance spectra were recorded over the complete day from 00:00 to 24:00 UTC simultaneously at the three locations west, center and east. The polar day at this high latitude site offers a unique and extremely valuable situation for such a $3-\mathrm{D}$ model comparison as the

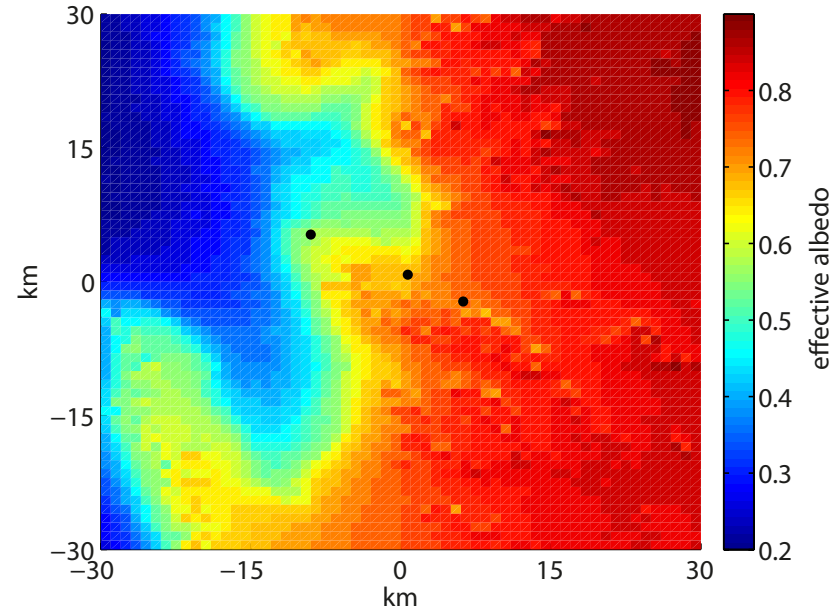

Figure 7. Effective albedo distribution around the measurement locations (three dots) derived from modeled global irradiances of a $60 \mathrm{~km} \times 60 \mathrm{~km}$ grid ("standard" scenario, SZA $=62^{\circ}$ ).

sun traces the complete $360^{\circ}$ azimuth angle range illuminating the landscape from all angles.

However, the high latitude also poses a challenge for both modeling and measuring the absolute global irradiance because of the generally large SZA $\left(62^{\circ}<\mathrm{SZA}<84^{\circ}\right)$. As the SZA approaches and exceeds $80^{\circ}$ several challenges appear for the modeling. First of all, great care must be taken in the calculation of the SZA. An SZA error of $0.1^{\circ}$ (e.g., when neglecting refraction of the atmosphere) results in errors of up to $3 \%$ in the global irradiance at $500 \mathrm{~nm}$ and $80^{\circ} \mathrm{SZA}$ and $1.5 \%$ at $70^{\circ}$ SZA. Comparing different available SZA algorithms (Duffett-Smith and Zwart, 2011; Blanco-Muriel et al., 2001; Spencer, 1971), we found differences of up to $0.3^{\circ}$. The algorithm of Reda and Andreas (2004) claims an uncertainty of below $0.001^{\circ}$ and agrees within $0.01^{\circ}$ with the one used in this study (Duffett-Smith and Zwart, 2011) which includes the refraction of a standard atmosphere.

Furthermore, with MYSTIC we use the plane-parallel approximation for the atmosphere which at $80^{\circ} \mathrm{SZA}$ induces a bias of up to $4 \%$ in the irradiances for the wavelength range between $340 \mathrm{~nm}$ and $500 \mathrm{~nm}$ (determined by comparing the irradiances from the 1-D discrete ordinate RT solver in libRadtran which can be run in both plane parallel and pseudospherical geometry). Also, the BRDF models are typically not validated for SZA above $80^{\circ}$ and might need different parameterization. This applies to the RPV of snow, while the Fresnel model for water is exact. The influence of aerosol and atmospheric vertical profiles on the global irradiance has been investigated and was found to be negligible (smaller than $0.6 \%$ at $\left.80^{\circ} \mathrm{SZA}\right)$.

The spectral measurements with DA spectrometers are also challenging at high SZA. First, the angular response (for direct radiation) of the global input optics deviates from an ideal cosine response specifically at angles exceeding $75^{\circ}$. 

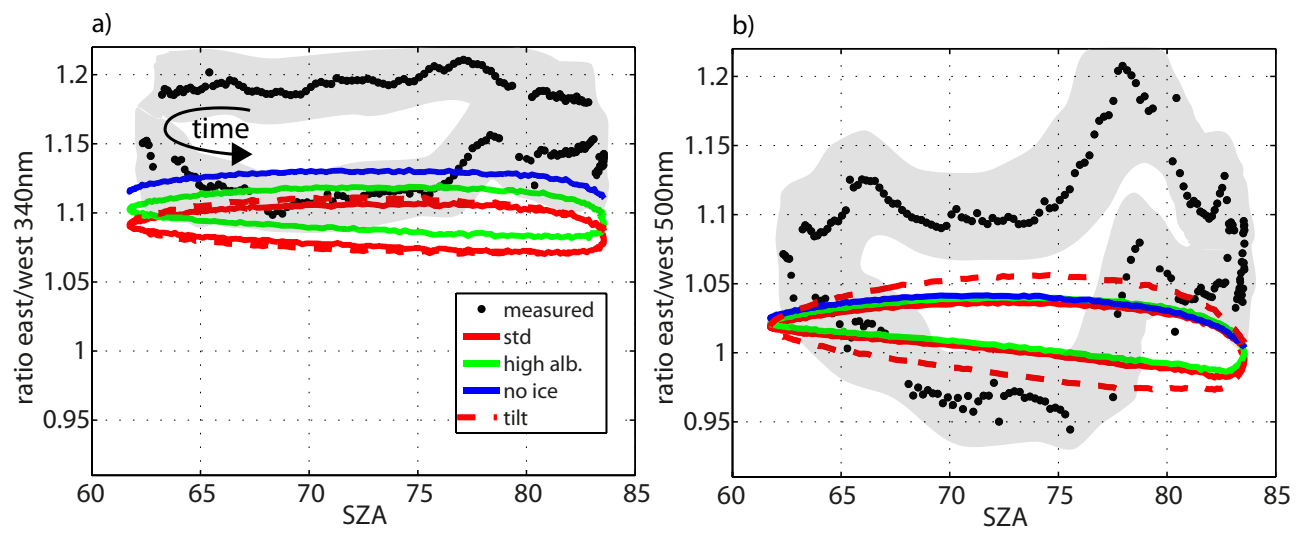

Figure 8. Ratios of global irradiances of stations east and west at wavelengths $340 \mathrm{~nm}$ (a) and $500 \mathrm{~nm}$ (b) plotted against SZA (black dots). The colored curves show the relevant model scenarios. The "no ice" scenario only applies to the morning. The legend refers to both plots (a) and (b). The measurement uncertainties are illustrated by gray shaded areas. Time progresses in counterclockwise direction along the curves that exhibit an interesting hysteresis.

The error is slightly larger for longer wavelengths (maximum $6 \%$ at $340 \mathrm{~nm}$ and $10 \%$ at $500 \mathrm{~nm}$ ), while also at longer wavelengths, the direct-to-diffuse ratio is larger, so the impact on the global irradiance is larger.

Second, stray light correction in the UV spectral range is generally a challenge in processing DA spectrometer data of solar measurements specifically at high SZA (Kreuter and Blumthaler, 2009). A longer optical path through the atmosphere generally implies an increased extinction with increasing effect for shorter wavelengths. So the cut-off wavelength, below which the signal counts are smaller than the noise (which is also dependent on stray light) increases with increasing SZA. Considering measurements up to $84^{\circ} \mathrm{SZA}$ and a rudimentary stray light correction method (as for east and center), the lower wavelength limit is $340 \mathrm{~nm}$ to ensure a reasonable error.

By taking ratios, the effects of all of the above problems can be reduced and we will, in particular, consider two types of ratios: ratios of irradiances between the different stations and the ratios between afternoon and morning irradiances with identical SZA at each station. In these ratios, the effects of SZA uncertainty, PP-approximation and cosine response errors are negligible. To minimize the uncertainty of absolute radiometric calibration, the ratios between the stations are also normalized to the ratios during the intercomparison day under clear-sky conditions.

\subsection{Irradiance ratios between locations}

The primary and well-known effect of the surface albedo is the enhancement of the global irradiance due to backscattering of reflected solar radiation. Spectrally, this effect increases with decreasing wavelength as the Rayleigh scattering cross section increases. The irradiance enhancement reaches a maximum at a wavelength of about $320 \mathrm{~nm}$. For shorter wavelengths, the tropospheric ozone absorption counterbalances the Rayleigh scattering and the albedo effect decreases again (Lenoble, 1998; Forster, 1995). The albedo amplification factor $\left(\mathrm{I}_{\mathrm{A}} / \mathrm{I}_{0}\right)$, the factor by which the irradiance $\mathrm{I}$ at albedo $\mathrm{A}$ is enhanced with respect to albedo 0 , is $(1+0.45 \times \mathrm{A})$ at $340 \mathrm{~nm}$ and $(1+0.15 \times \mathrm{A})$ at $500 \mathrm{~nm}$. So with albedo 0.3 , the irradiance is expected to increase by $14 \%$ at $340 \mathrm{~nm}$ and $5 \%$ at $500 \mathrm{~nm}$ relative to a non-reflecting surface. That factor is also weakly dependent on AOD and not perfectly linear with albedo but the deviations are small.

The ratios of global irradiances of east and west (EW ratios) at wavelengths $340 \mathrm{~nm}$ and $500 \mathrm{~nm}$ at common measurement times are plotted against SZA (at station west) in Fig. 8. The measured irradiances are averaged in a wavelength bandwidth of $5 \mathrm{~nm}$. The resulting ratios are normalized to the diurnal ratios of the instruments of the intercomparison day, which largely eliminates the influence of absolute calibration uncertainty and cosine error of the input optics. The measurement uncertainties are indicated by the gray bands. These include the relative stability of the instruments at stations east and west $(1.4 \%$ in the ratio at both wavelengths) and the uncertainties due to the stray light error $(1.4 \%$ in the ratio at $340 \mathrm{~nm})$ and the azimuth error of the global input optics $(2.1 \%$ and $1.4 \%$ in the ratio at $500 \mathrm{~nm}$ for $70^{\circ}$ and $80^{\circ} \mathrm{SZA}$, respectively). All uncertainties are independent, added quadratically and estimate the $1 \sigma$ standard deviation. The gap in the data around 12:00 UTC is the result of a power failure.

There are two features in Fig. 8 that we will focus on for the discussion of the data and the model scenarios: the diurnal variation and the average of the EW ratio. The first observation we discuss is the hysteresis-like behavior of the EW ratios. In both the measurement and all model scenarios for both wavelengths, the EW ratios depend on SZA and solar azimuth angle (i.e., the ratios are not symmetric around local noon). Time progresses in counterclockwise direction in the 

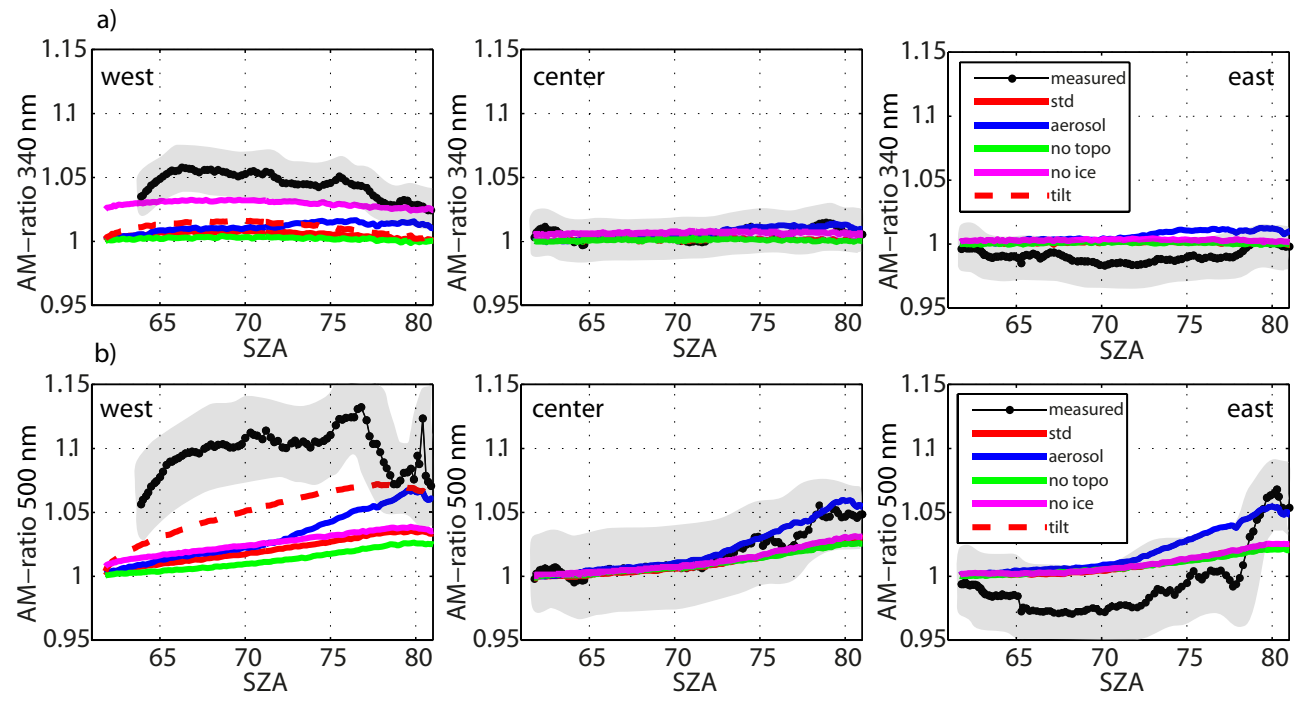

Figure 9. Ratios of afternoon/morning global irradiances (AM ratios) at stations west, center and east for wavelengths $340 \mathrm{~nm}$ (a) and $500 \mathrm{~nm}$ (b). Measured ratios (dots) are compared to the relevant model scenarios (colored curves). The legends apply to all panels. The measurement uncertainties are illustrated with gray shaded areas. The tilt scenario only applies to station west.

figure and the modeled EW ratios at $340 \mathrm{~nm}$ are higher in the morning than in the afternoon by $3-4 \%$. This is not expected from the effective albedos at this wavelength as they show little diurnal variation. At station west, the effective albedo is 0.56 in the morning and 0.58 in the afternoon at $70^{\circ} \mathrm{SZA}$, while at east, the difference between morning and afternoon albedo is less than 0.05 . From that consideration, the modeled EW ratio should be constant within $1 \%$ over the day.

This hysteresis is in fact the result of the local time shift between the stations. Measurements and simulations at each station are performed simultaneously at same UTC. The distance of $20 \mathrm{~km}$ between stations west and east corresponds to $0.7^{\circ}$ difference in longitude (at latitude $79^{\circ} \mathrm{N}$ ). This results in a shift of the local time of three minutes and a shift of the SZA diurnal variations with time. The SZA difference between west and east is a sinusoidal function of time with a maximum SZA difference of $0.15^{\circ}$ in the morning (at 07:00 UTC) and $-0.15^{\circ}$ in the afternoon (at 18:42 UTC). So even without any albedo effect, this SZA difference causes a higher relative global irradiance (east relative to west) in the morning than in the afternoon, more prominent at longer wavelengths because of the higher direct sun component in the irradiance.

Another effect along the same line is noticeable in Fig. 8b. At $500 \mathrm{~nm}$, all modeled EW ratio curves are slightly tilted towards lower ratios at high SZA and at SZA $>80^{\circ}$ in the afternoon, the ratios are even below one. While the effective albedo of east is always higher than at west (although the difference shrinks in the afternoon), it is the lower SZA at west in the afternoon that counterintuitively causes the irradiance there to be higher.
For the following discussion of the albedo effect we consider the average of the EW ratios. Over the entire day on average, the model "standard" scenario shows an enhanced global irradiance at station east compared to west, higher at $340 \mathrm{~nm}$ than at $500 \mathrm{~nm}$, as expected from the higher albedo environment in the east. The average effective albedos are 0.74 and 0.57 , respectively. The "standard" scenario predicts an EW ratio of 1.09 at $340 \mathrm{~nm}$ (9\% average enhancement) as shown in Fig. 8a. The measured ratio averaged for SZA $<75^{\circ}$ is 1.15 at $340 \mathrm{~nm}$. For $500 \mathrm{~nm}$, the average measured EW ratio in the same SZA range is 1.05 , which is close to the average ratios of the modeled scenarios of 1.02-1.03.

The "higher albedo" scenario considers a higher snow albedo (equivalent to a Lambertian albedo of 0.86), which increases the effective albedo difference between west and east and hence increases the modeled average EW ratio to 1.10 at $340 \mathrm{~nm}$. A similar effect is achieved by removing the ice in the morning in the Fjord ("no ice" scenario). In that scenario the effective albedo of the ocean is reduced in the morning, which predominantly reduces the effective albedo around station west before 12:00 UTC, and increases the model ratio by $1.5 \%$ relative to the standard scenario. Note that in the "no-ice" scenario also the hysteresis is increased. So a combination (effects can be added linearly to good approximation) of both scenarios "high albedo" and "no ice" yields the best comparison with the measurements.

Furthermore, we also investigate an uncertainty in the exact station positions. From the GPS positioning, station west is situated $1 \mathrm{~km}$ inland from the coast as given by the ice map, whereas from our judgment it was rather a little closer, possibly as close as $500 \mathrm{~m}$. The modeled global irradiance at west with a position $500 \mathrm{~m}$ north (i.e., closer to the coast) was 
decreased by $1 \%$, which would increase the EW ratio by another 0.01 . At the coast, the gradient of the effective albedo is highest (see Fig. 7), and the irradiance is very sensitive on the exact position. The irradiances of stations center and east are relatively insensitive to the position, as the effective albedo away from the coast line varies slowly with position.

Regarding the diurnal hysteresis of the EW ratio with SZA, we note that, at $340 \mathrm{~nm}$, the only way to model an increased hysteresis is the "no ice" scenario (in the morning and the "standard" scenario in the afternoon). This increases the EW ratio at $340 \mathrm{~nm}$ in the morning only and hence increases the difference of morning and afternoon ratios. At $500 \mathrm{~nm}$, the albedo has a lower impact and consequently, the drift ice significantly modifies neither the average EW ratio, nor the hysteresis.

From our range of plausible scenarios, the only possible cause for the higher observed hysteresis at $500 \mathrm{~nm}$ is a detector tilt. Routinely, the detectors are mounted with a leveling precision of $0.1^{\circ}$. However, the detector at station west was mounted on the roof of a small wooden cabin resting on the snow surface. The cabin could have been tilted during measurement phase due to an unequal compression of the snow pack below its base. The effect of a $0.5^{\circ}$ tilt of detector west towards west ("tilt" scenario) is shown in Fig. 8. The effect is $<1 \%$ for $340 \mathrm{~nm}$, because of the mainly diffuse sky at this wavelength. At $500 \mathrm{~nm}$, the direct proportion of the irradiance is larger and the magnitude of the hysteresis is increased by $4 \%$ at $75^{\circ}$ SZA. Even a larger tilt of $1^{\circ}$ cannot be excluded which would, to a good approximation, have double the effect and reproduce the magnitude of the observed hysteresis. Note that the azimuth error of the input optics has a similar effect as the tilt and also causes a hysteresis. This uncertainty can be of the order of $2 \%$ at $500 \mathrm{~nm}$ but is somewhat arbitrary to model and is considered within the measurement uncertainty.

The AOD variations are assumed and modeled equally for all stations ("aerosol" scenario). In principle, the AOD has an effect on the effective albedo, due to enhanced backscattering, but for low AOD, the impact can safely be neglected for the EW ratios here. Only for much higher optical depth such as for stratus clouds, the ratios would be affected.

Also very noticeable in the observed $\mathrm{EW}$ ratios are the prominent peaks between $75^{\circ}$ and $80^{\circ} \mathrm{SZA}$ in the morning and similarly in the afternoon. Both features are larger for $500 \mathrm{~nm}$ than for $340 \mathrm{~nm}$, which is typical for clouds. As mentioned, clouds were indeed faintly visible on the northwestern horizon and we modeled the effect of clouds and found that a homogeneous cloud cover at a minimal distance of $15 \mathrm{~km}$ northwest of station west affects the global irradiance ratios by less than $2 \%$ as long as it does not obscure the direct sun (which can be excluded from the sun photometer data). However, the effect depends on the cloud parameters, such as distance, height, thickness and optical depth and our assumptions are somewhat arbitrary by lack of more detailed cloud information.

\subsection{Afternoon / morning (AM) ratios}

The measured irradiances at each station are interpolated to an SZA grid with $0.1^{\circ}$ resolution so that ratios at the exact same SZA can be computed. These afternoon/morning ratios (A/M ratios) for each station (west, center and east) for the two wavelengths $340 \mathrm{~nm}$ and $500 \mathrm{~nm}$ are shown in Fig. 9. The measured ratios are averaged within a $10 \mathrm{~nm}$ wavelength bandwidth. The measurement uncertainties are indicated by the gray bands which are estimated as for the EW ratios except for the stray light error which is assumed equal for spectra at equal SZA and is rejected in the AM ratios.

For west, the measured global irradiance at $500 \mathrm{~nm}$ in the afternoon is $10 \%$ higher than in the morning between $67^{\circ} \mathrm{SZA}$ and $75^{\circ} \mathrm{SZA}$, while at $340 \mathrm{~nm}$, the difference is $5 \%$. This asymmetry is qualitatively reproduced in the "standard" model scenario but with a much smaller magnitude. At the other stations the AM ratios significantly deviate from 1 only at $500 \mathrm{~nm}$ and at SZAs around $80^{\circ}$. So we investigate the individual effects of the alternative model scenarios.

Most prominently, the "aerosol" scenario with a higher AOD in the morning around $80^{\circ}$ SZA has an almost $4 \%$ effect at $500 \mathrm{~nm}$. This is interesting, because the AOD at $500 \mathrm{~nm}$ was quite low and increased only by 0.05 from 0.12 to 0.17 . However, the small AOD difference has a large effect because the extinction of the direct radiation is an exponential function where the exponent is the product of AOD and air-mass factor. The air-mass factor defines the direct optical path length through the atmosphere as a ratio to the vertical path. At $80^{\circ} \mathrm{SZA}$, the (Rayleigh) air mass is 5.6. So by considering the attenuated direct radiation only, a $3 \%$ increase in the AM ratios would be estimated.

To estimate the effect of the drift ice for the AM ratios, we consider the scenario of drift ice in the Fjord in the afternoon (standard) and an ice-free Fjord in the morning (no ice). As noted above, the effect of the drift ice is an albedo effect and mainly affects the AM ratios of the west station at short wavelengths. At west it amounts to $3 \%$ at $340 \mathrm{~nm}$ and $70^{\circ} \mathrm{SZA}$ while at $500 \mathrm{~nm}$ the drift ice effect is smaller than $1 \%$.

As already indicated in the discussion of the EW ratios, the "tilt" scenario of the detector at the west station is plausible and reduces the model to measurement discrepancy. This is confirmed in the AM ratios, again especially at $500 \mathrm{~nm}$. At west, a tilt of $0.5^{\circ}$ (towards west) has a $4 \%$ maximum effect at $500 \mathrm{~nm}$ and $75^{\circ} \mathrm{SZA}$. At $340 \mathrm{~nm}$ the tilt effect is below $1 \%$, because of the predominantly diffuse sky radiance.

The scenario of higher albedo has no effect in AM ratios, as it only affects the quasi-Lambertian snow albedo, which is also independent of the solar azimuth angle. Also the topography around the locations is of minor influence; the only visible effect of $1 \%$ is for west at $500 \mathrm{~nm}$, and is negligible at the other stations. This is because at west the snow covered hills are to the southeast of the station, so they are illuminated by the sun only in the afternoon and increase the 
global irradiance for the longer wavelengths with a large direct radiation component. At $340 \mathrm{~nm}$ the irradiance mainly consists of a diffuse component which is independent on the solar azimuth angle. So the characteristic deviations from homogeneous albedo evident in afternoon morning asymmetries at high SZA are not a topography effect, but rather a sun glint effect. The characteristic signature is the increase of this effect with increasing wavelength and that it is most prominent at west closest to the ocean, and decreasing for the stations towards east. However, due to the low albedo sensitivity of long wavelengths, the effect remains small $(<3 \%$ at $500 \mathrm{~nm}$ ).

So at stations center and east, the AM ratios of the aerosol model scenario are in agreement with the measurements for both wavelengths within the measurement uncertainty. At station west, the combination of aerosol, drift ice and tilt, yields a satisfactory agreement of data and model. There are some remaining discrepancies between $75^{\circ}$ and $80^{\circ} \mathrm{SZA}$ which may be explained by high clouds, although from our cloud scenario, the ratios should not be affected by more than $3 \%$ at $500 \mathrm{~nm}$.

\section{Conclusions}

3-D radiative transfer model simulations and measurements of the global irradiance at three locations are compared for a full clear-sky day at the Arctic coast of Svalbard. The effective albedos for snow and water are modeled and show a strong dependence on wavelength and SZA. At $500 \mathrm{~nm}$, the effective albedo increases with SZA, in particular for water, which is the so-called sun glint. The sun glint causes a strong diurnal cycle of the effective albedo at long wavelengths. The albedo has the biggest impact at short wavelengths and the effective albedos at $340 \mathrm{~nm}$ increase from west to east, from 0.57 to 0.75 , constant within 0.02 over the day.

We observe the well-known albedo effect that the irradiance increases with increasing albedo. The measured ratios at $340 \mathrm{~nm}$ between stations east and west indicate an increase of the average irradiance of $15 \%$, which is higher than our model result from standard parameters for snow BRDF and drift ice on the ocean. In addition, the observed hysteresis with SZA, which we found to be an interesting result of a local time shift between the stations, exceeds our standard model prediction. The hysteresis emphasizes that irradiances, simultaneously measured at even relatively close locations, may be affected by the corresponding differences in the SZA, particularly for the typically large SZAs at high latitudes.

Modeling the observed drift ice-free Fjord in the morning increases both the average east-west (EW) ratio and the hysteresis. For the modeled average EW ratio to be within the measurement uncertainty the snow albedo should be higher still than our model scenario with a Lambertian equivalent snow albedo of 0.86 and is likely bigger than 0.9 . At $500 \mathrm{~nm}$, the average EW ratio is close to one. Since the albedo has a smaller influence on the irradiance the only plausible way to model a greater observed hysteresis is a tilt of the detector at station west of about $1^{\circ}$. This is plausible because the detector was mounted on the roof of a small wooden cabin with no permanent support on the frozen ground. The tilt has a similar effect as an azimuth error of the input optics.

The afternoon/morning (AM) ratios confirm the above conclusions. While these ratios are insensitive to the value of the snow albedo, increasing amount of drift ice during the day and the detector tilt are needed to explain the higher irradiance in the afternoon, especially at station west. Furthermore, the AM ratios illustrate the significant effect of small AOD variations at high SZA. Including these variations in a model scenario reduces the discrepancies between model and observations especially at stations center and east. The remaining discrepancies are possibly due to clouds on the northwestern horizon in the morning. Although in our particular modeled cloud scenario the cloud effect was small, different cloud parameters may lead to a higher effect. The AM ratios also illustrate the negligible effect of topography for our locations and that the prominent sun glint (evident in the effective albedos at $500 \mathrm{~nm}$ ) has only a minor effect on the global irradiances because of the low albedo sensitivity at long wavelengths.

In summary, we presented a unique multi-dimensional data set with respect to SZA (time), wavelength and position. Our study of global irradiances in a highly heterogeneous albedo environment shows that even for the relatively simple clear-sky situation, a variety of parameters have to be considered which illustrates the complexity of modeling solar irradiances at the Arctic coast. The associated uncertainties of both measurements and model input parameters conceal many of the model effects and reduce the suitability for a stringent validation of the 3-D model and BRDF parameterizations.

No doubt, more data of a series of at least two completely clear-sky days with stable atmospheric and sea ice conditions would be desirable to better constrain the model input. Measurement uncertainties are expected to be reduced by technological advancement of DA systems and improved input optics. This leaves room for future efforts to more accurately map the irradiance distribution along a large albedo gradient.

Acknowledgements. The campaign was realized within the ARCFAC project ARCFAC-026129-2009-32 and besides the financial funding, we would like to thank all the associated ARCFAC staff for the exceptional support and the ideal local infrastructure that was provided in Ny-Ålesund during our campaign. This includes the staff of the Norwegian Polar Institute and the Alfred Wegner Institute. We thank Christoph Wehrli for the original AOD data. We also thank the Chair of the Theoretical Meteorology in Munich for allowing us to use their computer cluster.

Edited by: S. Kazadzis 


\section{References}

Anderson, G., Clough, S., Kneizys, F., Chetwynd, J., and Shettle, E.: AFGL atmospheric constituent profiles $(0-120 \mathrm{~km})$, Tech. Rep. AFGL-TR-86-0110, Air Force Geophys. Lab., Hanscom Air Force Base, Bedford, Mass., 1986.

Blanco-Muriel, M., Alarcon-Padilla, D. C., Lopez-Moratella, T., and Lara-Coira, M.: Computing the solar vector, Solar Energy, 70, 431-441, 2001.

Bernhard, G., Booth, C. R., Ehramjian, J. C., Stone, R., and Dutton, E. G.: Ultraviolet and visible radiation at Barrow, Alaska: Climatology and influencing factors on the basis of version $2 \mathrm{Na}-$ tional Science Foundation network data, J. Geophys. Res., 112, D09101, doi:10.1029/2006JD007865, 2007.

Blumthaler, M.: Factors, trends and scenarios of UV radiation in Arctic-alpine environments, in Arctic Alpine Ecosystems and people in a changing Environment, Springer Berlin, 181-193, 2007.

Blumthaler, M. and Ambach, W.: Solar UVB-albedo of various surfaces, Photochem. Photobiol., 48, 85-88, 1988.

Buras, R. and Mayer, B.: Efficient unbiased variance reduction techniques for Monte Carlo simulations of radiative transfer in cloudy atmospheres: The solution, J. Quant. Spect. Rad. Trans., 112, 3, 434-447, 2011.

Carroll, J. J., and Fitch, B. W.: Effects of solar elevation and cloudiness on snow albedo at the South Pole, J. Geophys. Res., 86, 5271-5276, doi:10.1029/JC086iC06p05271, 1981.

Cox, C. and Munk, W.: Measurement of the roughness of the sea surface from photographs of the sun's glitter, J. Opt. Soc. Am., 44, 838-850, 1954.

Degünther, M., Meerkötter, R., Albold, A., and Seckmeyer, G.: Case Study on the influence of inhomogeneous surface albedo on UV irradiance, Geophys. Res. Lett., 25, 3587-3590, 1998.

Degünther, M. and Meerkötter, R.: Influence of inhomogeneous surface albedo on UV irradiance: Effect of a stratus cloud, J. Geophys. Res., 105, D18, 22755-22761, 2000.

Duffett-Smith, P. and Zwart, J.: Practical Astronomy with your calculator, Cambridge University Press, 2011.

Forster, P. M. De F.: Modeling Ultraviolet Radiation at the Earth's Surface. Part I: The Sensitivity of Ultraviolet Irradiances to Atmospheric Changes. J. Appl. Meteor., 34, 2412-2425, 1995.

Gröbner, J., Hülsen, G., Wuttke, S., Schrems, O., De Simone, S., Gallo, V., Rafanelli, C., Petkov, B., Vitale, V., Edvardsen, K., and Stebel, K.: Quality assurance of solar UV irradiance in the Arctic, Photochem. Photobiol., 9, 384-391, 2010.

Hale, G. M. and Querry, M. R.: Optical Constants of Water in the 200-nm to 200-mum Wavelength Region, Appl. Opt. 12, 555563,1973

Hecht, E.: Optics, Addison-Wesley Longman, 2002.

Huber, M., Blumthaler, M., Schreder, J., Schallhart, B., and Lenoble, J.: Effect of inhomogeneous surface albedo on diffuse UV sky radiance at a high-altitude site, J. Geophys. Res., 109, D08107, doi:10.1029/2003JD004013, 2004.

Kirk, J.T.O.: Light and photosynthesis in aquatic ecosystems, 2nd edn. Cambridge University Press, Cambridge, 1994.

König-Langlo, G. and Herber,A.: Bipolar Intercomparison of longterm solar radiation measurements from two BSRN stations, paper presented at the 9th Science and Review Workshop for the BSRN, Lindenberg, Germany, 29 May-2 June 2006.
Kouremeti, N., Bais, A., Kazadzis, S., Blumthaler, M., and Schmitt, R.: Charge-coupled device spectrograph for direct solar irradiance and sky radiance measurements, Appl. Opt., 47, 15941607, 2008.

Kreuter, A. and Blumthaler, M.: Stray light correction for solar measurements using array spectrometers, Rev. Sci. Instr., 80, 096108 , doi:10.1063/1.3233897, 2009.

Kreuter, A., Zangerl, M., Schwarzmann, M., and Blumthaler, M.: All-sky imaging: A simple versatile system for atmospheric research, Appl. Opt., 48, 6, 1091-1097, 2009.

Kylling, A. and Mayer, B.: Ultraviolet radiation in partly snow covered terrain: Observations and three-dimensional simulations, Geophys. Res. Lett., 28, 3665-3668, 2001.

Lenoble, J.: Modeling of the Influence of Snow Reflectance on Ultraviolet Irradiance for Cloudless Sky, Appl. Opt., 37, 24412447, 1998.

Marchuk, G. I., Mikhailov, G. A., and Nazaraliev, M. A.: The Monte Carlo methods in atmospheric optics. Springer Series in Optical Sciences, Berlin, Springer, 1980.

Mayer, B. and Degünther, M.: Comment on "Measurements of erythemal irradiance near Davis Station, Antarctica: Effect of inhomogeneous surface albedo", Geophys. Res. Lett., 27, 34893490, 2000.

Mayer, B.: Radiative transfer in the cloudy atmosphere. Euro. Phys. J. Conf., 1, 75-99, 2009.

Mayer, B., Hoch, S. W., and Whiteman, C. D.: Validating the MYSTIC three-dimensional radiative transfer model with observations from the complex topography of Arizona's Meteor Crater, Atmos. Chem. Phys., 10, 8685-8696, 2010, http://www.atmos-chem-phys.net/10/8685/2010/.

Mayer, B. and Kylling, A.: Technical note: The libRadtran software package for radiative transfer calculations - description and examples of use, Atmos. Chem. Phys., 5, 1855-1877, doi:10.5194/acp-5-1855-2005, 2005.

McKenzie, R. L., Paulin, K. J., and Madronich S.: Effects of snow cover on UV irradiance and surface albedo: A case study, J. Geophys. Res., 103, 28785-28792, 1998.

Meinander, O., Kontu, A., Lakkala, K., Heikkilä, A., Ylianttila, L. and Toikka, M.: Diurnal variations in the UV albedo of Arctic snow, Atmos. Chem. Phys., 8, 6551-6563, doi:10.5194/acp-86551-2008, 2008.

Overland, J. E., Curtin, T. B., and Smith, W. O. (eds): Special section: Leads and Polynyas, J. Geophys. Res., 100, 4267-4843, 1995.

Podgorny, I. and Lubin, D.: Biologically active insolation over Antarctic waters: Effect of a highly reflecting coastline, J. Geophys. Res., 103, 2919-2928, 1998.

Rahman, H., Pinty, B., and Verstraete, M. M.: Coupled surface atmosphere reflectance (CSAR) model, 2, Semiempirical surface model usable with NOAA advanced very high resolution radiometer data, J. Geophys. Res., 98, 20791-20801, 1993.

Reda, I. and Andreas, A.: Solar Position Algorithm for Solar Radiation Applications, Solar Energy, 76, 577-589, 2004.

Reuder, J., Ghezzi, F., Palenque, E., Torrez, R., Andrade, M., and Zaratti, F.: Investigations on the effect of high surface albedo on erythemally effective UV irradiance: Results of a campaign at the Salar de Uyuni, Bolivia, Photochem. Photobiol. B, 87, 1-8, 2007. 
Ricchiazzi, P. and Gautier, C.: Investigation of the effect of surface heterogeneity and topography on the radiation environment of Palmer Station, Antartica, with a hybrid 3-D radiative transfer model, J. Geophys. Res., 103, 6161-6176, 1998.

Ricchiazzi, P., Payton, A., and Gautier C.: A test of threedimensional radiative transfer simulation using the radiance signatures and contrasts at a high latitude coastal site, J. Geophys. Res., 107, 4650, doi:10.1029/2001JD001166, 2002.

Shettle, E.: Models of aerosols, clouds and precipitation for atmospheric propagation studies, in: Atmospheric propagation in the $\mathrm{UV}$, visible, IR and mm-region and related system aspects, no. 454 in AGARD Conference Proceedings, 1989.

Smolskaia, I., Nunez, M., and Michael, K.: Measurements of erythemal irradiance near Davis Station, Antarctica: Effect of inhomogeneous surface albedo, Geophys. Res. Lett., 26, 1381-1384, 1999.

Shettle, E.: Models of aerosols, clouds and precipitation for atmospheric propagation studies, in: Atmospheric propagation in the UV, visible, ir and mm-region and related system aspects, No. 454 in AGARD Conference Proceedings, 1989.

Slaper, H., Reinen, H. A. J. M., Blumthaler, M., Huber, M., and Kuik, F.: Comparing ground-level spectrally resolved solar UV measurements using various instruments: A technique resolving effects of wavelength shift and slit width. Geophys. Res. Lett., 22, 2721-2724, 1995.
Spencer, J. W.: Fourier series representation of the position of the sun, Search, 2, 5, 1971.

Walker, J.: Colour Rendering of Spectra, http://www.fourmilab.ch/ documents/specrend, 2003.

Wang, X. and Zender, C. S.: Arctic and Antarctic diurnal and seasonal variations of snow albedo from multiyear Baseline Surface Radiation Network measurements, J. Geophys. Res., 116, F03008, doi:10.1029/2010JF001864, 2011.

Warren, S. G., Brandt, R. E., and O'Rawe Hinton, P.: Effect of surface roughness on bidirectional reflectance of Antarctic snow. J. Geophys. Res., 103, 789-807, 1998.

Weihs, P., Lenoble, J., Blumthaler, M., Martin, T., Seckmeyer, G., Philipona, R., De la Casiniere, A. Sergent, C., Gröbner, J., Cabot, T., Masserot, D., Pichler, T., Pougatch, E., Rengarajan, G., Schmucki, D., and Simic, S.: Modeling the effect of an inhomogeneous surface albedo on incident UV radiation in mountainous terrain: Determination of an effective surface albedo. Geophys. Res. Lett., 28, 3111-3114, 2001.

Wiscombe, W.J. and Warren, S.G.: A model for the spectral albedo of snow, I. pure snow. J. Atmos. Sci., 37, 2712-2733, 1980.

Wuttke, S., Seckmeyer, G., and König-Langlo, G.: Measurements of spectral snow albedo at Neumayer, Antarctica, Ann. Geophys., 24, 7-21, doi:10.5194/angeo-24-7-2006, 2006. 